\title{
Microbial Colonies in Renal Stones
}

\author{
A. Izatulina ${ }^{1(\bowtie)}$, M. Zelenskaya ${ }^{2}$, and O. Frank-Kamenetskaya ${ }^{1}$ \\ ${ }^{1}$ Department of Crystallography, St. Petersburg State University, \\ St. Petersburg, Russia \\ alina.izatulina@mail.ru \\ 2 Department of Botany, St. Petersburg State University, St. Petersburg, Russia
}

\begin{abstract}
The presence and study of the species composition of bacterial and fungal colonies in renal stones was determined. It was shown that the presence of microorganisms depends on the phase composition of the renal stone. No microbial colonies were detected in oxalate stones. Under the action of the acidproducing bacterial and fungal colonies, secondary crystallization of calcium oxalates (whewellite and weddellite) on phosphate aggregates can occur.
\end{abstract}

Keywords: Renal stones - Calcium oxalates - Crystallization · Phosphate renal stones $\cdot$ Microorganisms

\section{Introduction}

Interest in pathogenic crystallization is growing every year, which is primarily due to the wide prevalence of diseases associated with stone formation, such as urolithiasis. Very few works are devoted to the influence of bacteria, viruses and micromycetes on stone formation in the human body. Thus, Sagorika et al. (2013) described a patient with renal aspergillosis along with urolithiasis, Zhao et al. (2014) reported on the crystallization of calcium oxalate in the presence of $E$. coli. Other studies have noted the initiation of calcium oxalate crystallization and aggregation in the presence of E. coli. Most of the known works are devoted to the so-called infectious renal stones, consisting mainly of struvite, and sometimes containing hydroxylapatite and brushite.

\section{Methods and Approaches}

The study was conducted using 21 samples of renal stones of different composition: 10 - oxalate, 5 - urate, and 6 - phosphate stones.

The substance of renal stones was sieved on the Czapek-Dox medium, potato glucose agar and Saburo medium to detect the presence and to determine the species composition of microorganisms. Preparation of nutrient media was carried out in accordance with GOST (GOST 9.048-89). The media was sterilized in an autoclave after preparation. After incubation period (20 days, 1 month), the samples were microscoped and examined in accordance with identifier (de Hoog and Guarro 1995).

Powder x-ray diffraction (PXRD) studies were carried out using the Rigaku «MiniFlex II» diffractometer $(\mathrm{CuK} \alpha$ radiation of wavelength $\lambda=1.54178 \AA$, X-ray 
tube parameters were $30 \mathrm{kV} / 15 \mathrm{~mA}$; highspeed solid state energy-dispersive detector LYNXEYE was used). X-ray diffraction patterns were collected at room temperature in the range of $2 \theta=5-50^{\circ}$ with a step of $0.02^{\circ} 2 \theta$ and a counting time of half second per data point, the specimens were rotated 30 times per second during the data collection.

\section{Results and Discussion}

As the result of urate and oxalate renal stones sieving, the detection of micromycetes on the surface of the nutrient medium was random, and revealed a very small number of fungal colonies; the species of micromycetes were not constant. Abundant growth of fungal and bacterial colonies was detected on the phosphate renal stones: Cladosporium cladosporioides, Penicillium expansum, Aspergillus niger, sporiferous light colored fungus, Geotrichum candidum, Candida sp., Fusarium chlamydosporum, Cladosporium sphaerospermum, white and pink bacterial colonies (Fig. 1). Secretion of micromycetes on the surface of the nutrient medium was probably accidental, in many cases an insignificant number of fungal colonies was detected (1-3 colonies), the species distribution of micromycetes was not constant. There is a probability that some types of identified micromycetes (Aspergillus niger, Cladosporium sphaerospermum, Phoma herbarum, Penicillium purpurogemum, Penicillium expansum, Fusarium chlamydosporum) accidentally hit the test renal stone material (for instance, as a result of transportation or storage). The secretion of bacterial colonies and colonies of the fungus Candida sp., is most likely not accidental, since a number of recent works indicate the possibility of a bacterial biofilm formation on the surface of renal (urinary) stones (Romanova et al. 2015). The possibility of micromycetes detection on the surface of renal stones within the microorganisms' biofilm requires further investigation.

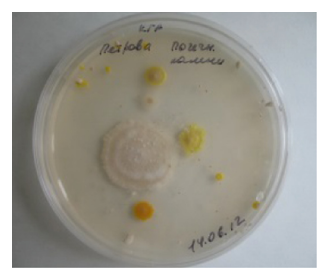

Fig. 1. Phosphate renal stone sample. The growth of bacterial and micromycetes colonies on the surface of the nutrient medium in a Petri dish $(\varnothing 100 \mathrm{~mm})$.

A colony of Aspergillus niger micromycetes was found on a nutrient medium on one of the phosphate samples, consisting of hydroxylapatite, struvite and brushite. Aspergillus infections have grown in importance in the last years (Hedayati et al. 2007). Oxalate crystals may be present in clinical samples, due to the high acidproducing ability of this fungus. When Aspergillus niger is growing on a liquid nutrient medium, it was found that acidification of the culture fluid begins almost immediately after spore germination and continues during the whole period of mycelium active growth. After a month of incubation (Fig. 2), under the influence of Aspergillus niger 
culture, the renal stone softens and many small crystals are observed during microscopy. According to the results of PXRD analysis, the observed crystals turned out to be mainly calcium oxalate dihydrate (weddellite); crystals of calcium oxalate monohydrate (whewellite) are also present but in subordinate quantities. Thus, under the influence of the Aspergillus niger culture, secondary crystallization of calcium oxalate occurs on a phosphate renal stone. The secondary crystallization of calcium oxalates under the action of microscopic fungi was recently described for monuments of cultural heritage (Rusakov et al. 2016). This phenomenon may be one of the reasons for the frequent presence of a phosphate nucleus in the center of an oxalate renal stones (Izatulina and Yelnikov 2008; Xie et al. 2014).

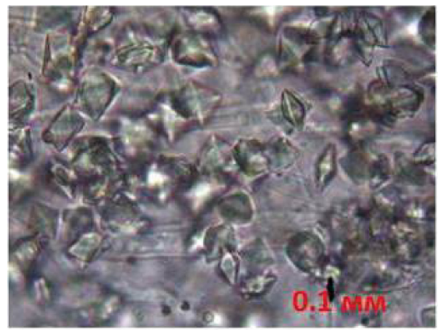

a

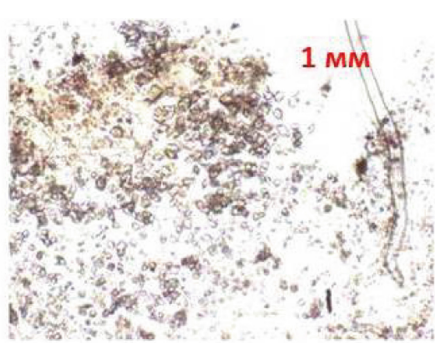

b

Fig. 2. The formation of calcium oxalate crystals in the presence of Aspergillus niger and a nondisrupting light-colored fungus during growth on a nutrient medium in a Petri dish (potato glucose agar was used as a nutrient medium).

\section{Conclusions}

Bacterial and fungal colonies were found on the surface of phosphate renal stones; no microbial colonies were found in oxalate and urate stones. It has been shown for the first time that under the influence of the microscopic fungus Aspergillus niger, secondary crystallization of calcium oxalates (whewellite and weddellite) can occur on phosphate aggregates. Thus, the possibility of the oxalate stones formation on phosphate nuclei with the participation of acid-producing bacterial and fungal colonies was shown.

Acknowledgements. This work was supported by the Russian Science Foundation (no. 18-7700026). The XRD studies have been performed at the X-ray Diffraction Centre of St. Petersburg State University.

\section{References}

Bonaventura M, Gallo M, Cacchio P, Ercole C, Lepidi A (1999) Microbial formation of oxalate films on monument surfaces: bioprotection or biodeterioration? Geomicrobiology 16:55-64

De Hoog GS, Guarro J (1995) Atlas of clinical fungi, Baarn 
Hedayati MT, Pasqualotto AC, Warn PA, Bowyer P, Denning DW (2007) Aspergillus flavus: human pathogen, allergen and mycotoxin. Microbiology 153:1677-1692

Izatulina AR, Yelnikov VY (2008) Structure, chemistry and crystallization conditions of calcium oxalates - the main components of kidney stones. In: Krivovichev SV (ed) Minerals as Advanced Materials I. Springer-Verlag, Heidelberg, pp 231-241

Romanova YuM, Mulabaev NS, Tolordava ER, Seregi AV, Seregin IV, Alexeeva NV, Stepanova TV, Levina GA, Barhatova OI, Gamova NA, Goncharova SA, Didenko LV, Rakovskaya IV (2015) Microbial communities on kidney stones. Molekulyarnaya Genetika, Mikrobiologiya i Virusologiya 33(2):20-25

Rusakov AV, Vlasov AD, Zelenskaya MS, Frank-Kamenetskaya OV (2016) The crystallization of calcium oxalate hydrates formed by interaction between microorganisms and minerals. In: Frank-Kamenetskaya OV, Panova EG, Vlasov DY (eds) Biogenic-Abiogenic Interactions in Natural and Anthropogenic Systems. Springer International Publishing, Switzerland, pp 357377

Sagorika P, Viswajeet S, Satyanarayan S, Manish G (2013) Renal aspergillosis secondary to renal instrumentation in immunocompetent patient. BMJ Case Rep 2013:bcr2013200306

Xie B, Halter TJ, Borah BM, Nancollas GH (2014) Aggregation of calcium phosphate and oxalate phases in the formation of renal stones. Cryst Growth Des 15(6):3038-3045

Zhao Z, Xia Y, Xue J, Qingsheng Wu (2014) Role of E. coli-secretion and melamine in selective formation of $\mathrm{CaC} 2 \mathrm{O} 4 \cdot \mathrm{H} 2 \mathrm{O}$ and $\mathrm{CaC} 2 \mathrm{O} 4 \cdot 2 \mathrm{H} 2 \mathrm{O}$ crystals. Cryst Growth Des 14:450-458

Open Access This chapter is licensed under the terms of the Creative Commons Attribution 4.0 International License (http://creativecommons.org/licenses/by/4.0/), which permits use, sharing, adaptation, distribution and reproduction in any medium or format, as long as you give appropriate credit to the original author(s) and the source, provide a link to the Creative Commons license and indicate if changes were made.

The images or other third party material in this chapter are included in the chapter's Creative Commons license, unless indicated otherwise in a credit line to the material. If material is not included in the chapter's Creative Commons license and your intended use is not permitted by statutory regulation or exceeds the permitted use, you will need to obtain permission directly from the copyright holder.

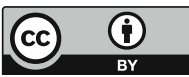

